\title{
Structure and Thermodynamics of Niobium Nitride in Equilibrium with Liquid Fe-Nb-N Alloy
}

\author{
By W.-G. Jung*, Y. Kita**, T. Tanaka** and Z. Morita**
}

\begin{abstract}
From the viewpoint of a fundamental study of steelmaking, the direct determination of the structure of niobium nitride in equilibrium with liquid $\mathrm{Fe}-\mathrm{Nb}-\mathrm{N}$ alloy has been carried out by means of high temperature X-ray diffraction technique. A thermodynamic analysis on the equilibrium between liquid $\mathrm{Fe}-$ $\mathrm{Nb}-\mathrm{N}$ alloy and niobium nitride has been attempted using the sublattice subregular model.

It was found that the niobium nitride equilibrating with liquid $\mathrm{Fe}-(10 \sim 20)$ mass $\% \mathrm{Nb}-\mathrm{N}$ alloy at $1813 \mathrm{~K}$ under the nitrogen pressure of $0.2 \sim 0.6 \times 10^{5} \mathrm{~Pa}$ existed as the $\delta$ phase with fcc structure. From both the lattice parameter and the thermodynamic analysis it was estimated that the composition of the niobium nitride in equilibrium with liquid $\mathrm{Fe}-\mathrm{Nb}-\mathrm{N}$ alloy at $1813 \mathrm{~K}$ changes monotonously from $\mathrm{NbN}_{0.8}$ to $\mathrm{NbN}_{0.9}$ with the variation of nitrogen pressure from $0.2 \times 10^{5}$ to $1.0 \times 10^{5} \mathrm{~Pa}$.
\end{abstract}

(Received April 13, 1988)

\begin{abstract}
Keywords: liquid iron-niobium-nitrogen alloy, niobium nitride, $X$-ray diffraction, high temperature, crystal structure, lattice parameter, non-stoichiometry, sublattice model, phase equilibrium
\end{abstract}

\section{Introduction}

It is well-known that niobium has very strong affinity to nitrogen, forms a stable nitride in steel, and thus improves the properties of the steel ${ }^{(1)-(4)}$. A complete understanding of the behavior of the niobium nitride is one of the very important problems in the steelmaking process.

In our previous study ${ }^{(5)}$, we investigated the structure and composition of the niobium nitride in equilibrium with liquid $\mathrm{Fe}-\mathrm{Nb}-\mathrm{N}$ alloy at $1813 \mathrm{~K}$ under one atmospheric pressure of nitrogen by means of high temperature X-ray diffractometry. Under the above experimental conditions, it was found that niobium nitride existed as the $\delta$ phase with the fcc structure, and the composition of niobium nitride was deduced to be $\mathrm{Nb}_{1.1} \mathrm{~N}$ according to the relation between the lattice parameter and the ratio of $\mathrm{N} / \mathrm{Nb}$.

It should be noted that the phase and com-

* Graduate Student, Osaka University, 2-1 Yamadaoka, Suita, Osaka 565, Japan.

** Department of Materials Science and Processing, Faculty of Engineering, Osaka University, 2-1 Yamada-oka, Suita, Osaka 565, Japan. position of niobium nitride equilibrating with liquid $\mathrm{Fe}-\mathrm{Nb}-\mathrm{N}$ alloy will vary with the change of the equilibrium condition such as temperature and pressure of nitrogen, since niobium nitride is non-stoichiometric and has various phases $^{(6)-(8)}$. From this point of view, in the present work, we have investigated the structure of niobium nitride in equilibrium with liquid $\mathrm{Fe}-$ $\mathrm{Nb}-\mathrm{N}$ alloy under various nitrogen pressure from $0.2 \times 10^{5}$ to $0.6 \times 10^{5} \mathrm{~Pa}$ by means of high temperature X-ray diffraction technique.

In general, a complete thermodynamic description of the equilibrium of nitride forming reaction requires a precise knowledge on the composition of nitride. However, it is very difficult to obtain precise experimental data on the composition of niobium nitride in equilibrium with liquid $\mathrm{Fe}-\mathrm{Nb}-\mathrm{N}$ alloy at high temperature. Therefore, in the present study, a thermodynamic analysis on the equilibrium between liquid $\mathrm{Fe}-\mathrm{Nb}-\mathrm{N}$ alloy and niobium nitride has been carried out, and the composition of niobium nitride has been estimated.

\section{Experimental}

An X-ray diffraction apparatus and experimental procedures are essentially the same as those described in the previous publication ${ }^{(5)}$. 
Some details concerning this study are given below.

The electrolytic iron of about $32 \mathrm{~g}$ was heated and melted in an alumina crucible, mounted in the goniometer, under $\mathrm{Ar}-40 \% \mathrm{H}_{2}$ atmosphere. A mixture of niobium and niobium nitride powder was added into liquid iron, then nitrogen gas of a fixed partial pressure was introduced in place of $\mathrm{Ar}-40 \% \mathrm{H}_{2}$ gas to form niobium nitride on the surface of liquid $\mathrm{Fe}-\mathrm{Nb}-\mathrm{N}$ alloy. After holding the specimen long enough to attain the equilibrium of nitride forming reaction, high temperature X-ray diffraction was performed on niobium nitride using $\mathrm{Mo}-\mathrm{K} \alpha$ radiation. The diffraction measurement were carried out at $1813 \mathrm{~K}$, as in the previous work, and at the nitrogen pressure of $0.2 \times 10^{5}, 0.3 \times 10^{5}$ and $0.6 \times 10^{5} \mathrm{~Pa}$. The nitrogen pressure was regulated by the ratio of flow rates of nitrogen gas and $\mathrm{Ar}-40 \% \mathrm{H}_{2}$ gas.

The mixture of niobium and niobium nitride powder weighing $8 \sim 9 \mathrm{~g}$, more than that used in the previous work, was used to form a liquid alloy of $(18 \sim 20)$ mass $\% \mathrm{Nb}$ as a nominal concentration, since the equilibrium niobium concentration may be higher than that in the previous work owing to lower nitrogen pressure.

In order to investigate a phase transformation in the course of cooling and solidification, niobium nitride was extracted from the surface of the ingot cooled and solidified at the rate of $3 \sim 7 \mathrm{~K} / \mathrm{s}$ after high temperature X-ray diffraction, and X-ray diffraction was carried out for the niobium nitride at room temperature with $\mathrm{Mo}-\mathrm{K} \alpha$ and $\mathrm{Cu}-\mathrm{K} \alpha$ radiations.

The nitrogen content of the solidified alloy was determined by the carrier gas thermal conductivity method. The niobium content of the alloy was determined both by the niobium pentoxide gravimetric method and by the inductively coupled plasma spectrophotometry.

The lattice parameter of niobium nitride was determined by an analytical method devised by Cohen, as described in the previous paper ${ }^{(5)}$.

The chemical composition of the materials used in the present study were the same as those used in the previous study.

\section{Experimental Results and Discussion}

\section{High temperature $\mathrm{X}$-ray diffraction}

Generally, a question may arise concerning the establishment of equilibrium between niobium nitride and liquid $\mathrm{Fe}-\mathrm{Nb}-\mathrm{N}$ alloy during high temperature $\mathrm{X}$-ray diffraction measurement, since the specimens were melted with resistance furnace in this experiment, not induction furnace with which the equilibrium is attained easily due to violent mixing of melt. In order to examine the attainment of equilibrium between liquid $\mathrm{Fe}-\mathrm{Nb}-\mathrm{N}$ alloy and niobium nitride during high temperature $\mathrm{X}$-ray diffraction experiment, therefore, niobium and nitrogen concentrations are compared in Fig. 1 between the results of this experiment and those obtained previously with induction furnace by one of the authors ${ }^{(9)}$. The present results were obtained for the $\mathrm{Fe}-\mathrm{Nb}-\mathrm{N}$ alloy solidified after the experiment at $1813 \mathrm{~K}$, and the previous results were obtained by extrapolation to $1813 \mathrm{~K}$ from experimental values at $1873 \sim 1973$ K. As shown in Fig. 1, the present results are in good agreement with the previous ones. Therefore, it was considered that the present results also gave the niobium and nitrogen concentrations in liquid $\mathrm{Fe}-\mathrm{Nb}-\mathrm{N}$ alloys equilibrating with niobium nitride, and high temperature X-ray diffraction had been performed under the equilibrium condition.

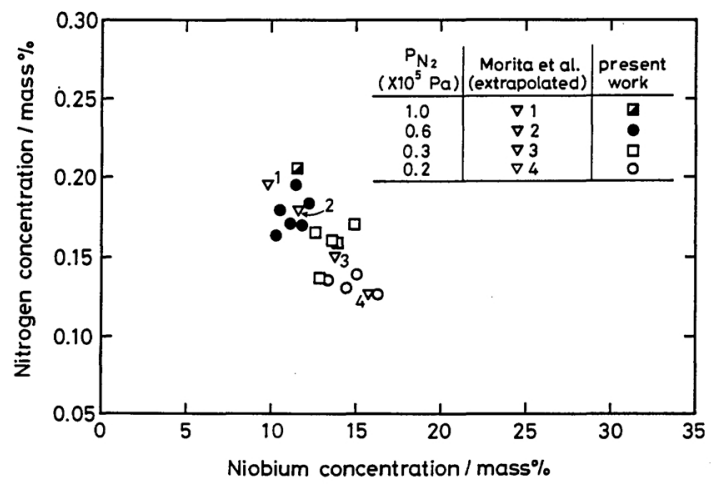

Fig. 1 Comparison of the results in the present work with those in the previous work on equilibrium concentrations of niobium and nitrogen in $\mathrm{Fe}-\mathrm{Nb}-\mathrm{N}$ alloys at $1813 \mathrm{~K}$. 
As mentioned before (II), the initial concentration of the liquid alloy was about 20 mass $\% \mathrm{Nb}$ at maximum, and niobium content in liquid alloy seemed to decrease gradually to the equilibrium concentration with the progress of nitride formation. The equilibrium niobium concentration in liquid alloy was about 10 mass $\% \mathrm{Nb}$ at minimum. Consequently, in the present paper, the liquid $\mathrm{Fe}-$ $\mathrm{Nb}-\mathrm{N}$ alloy always stands for the liquid $\mathrm{Fe}-$ (10 20) mass\% $\mathrm{Nb}-\mathrm{N}$ alloy.

As described in the previous paper ${ }^{(5)}$, most of the diffraction patterns obtained in the present experiments have also shown the effect of preferred orientation, and a normal diffraction pattern without influence of preferred orientation was obtained only in a few separate experimental runs. However the normal patterns obtained under the same equilibrium condition have shown good reproducibility. Typical examples of these normal patterns will be used for the discussion described below.

Figure 2(a), (b) and (c) show typical X-ray diffraction patterns of the niobium nitride in equilibrium with liquid $\mathrm{Fe}-\mathrm{Nb}-\mathrm{N}$ alloy at $1813 \mathrm{~K}$ under the nitrogen pressure of $0.2 \times 10^{5}, 0.3 \times 10^{5}$ and $0.6 \times 10^{5} \mathrm{~Pa}$, respectively. Figure 2(d) shows an X-ray diffraction pattern obtained in the previous experiment ${ }^{(5)}$ at $1813 \mathrm{~K}$ under one atmospheric pressure of nitrogen. Figure 2(e) and (f) show reference patterns for $\delta$ and $\gamma$ niobium nitride respectively, estimated from the data by Brauer et $a l .{ }^{(6)(10)}$ As obvious from Fig. 2, the X-ray diffraction patterns obtained from the present experiments (Fig. 2(a), (b) and (c)) agreed with one another and also agreed with the X-ray pattern obtained in the previous work (Fig. 2(d)), except a slight disagreement in relative intensity. Furthermore, each peak in all of these patterns corresponds well to that for $\delta$ phase (Fig. 2(e)) having fcc structure, and shows remarkable disagreement with that for $\gamma$ phase (Fig. 2(f)) having tetragonal structure. Consequently, from the present and previous results of the direct measurements of the diffraction patterns of niobium nitride at high temperature, it was confirmed that the niobium nitride existed as $\delta$ phase (fcc), not as $\gamma$ phase (tetragonal), in equilibrium with liquid $\mathrm{Fe}-$

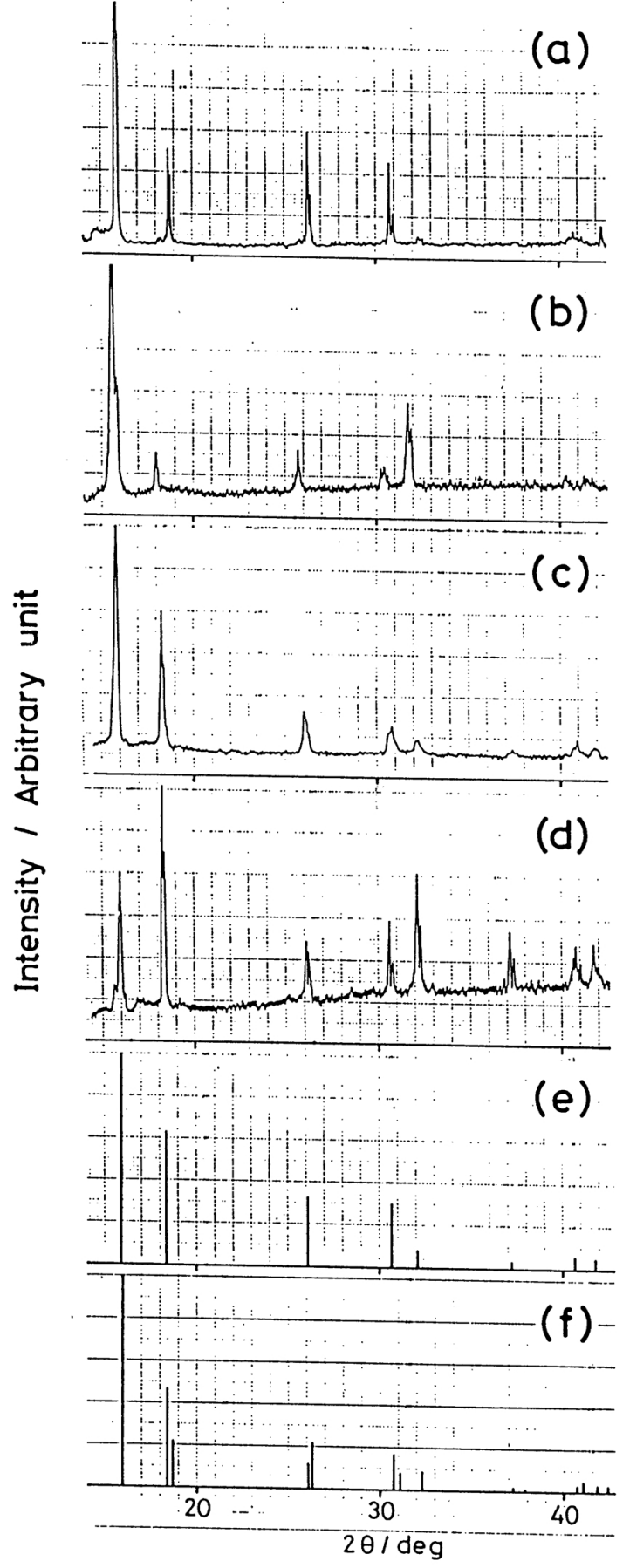

Fig. 2 X-ray diffraction patterns from niobium nitride in equilibrium with liquid $\mathrm{Fe}-\mathrm{Nb}-\mathrm{N}$ alloy at $1813 \mathrm{~K}$ under various pressure of nitrogen $(\mathrm{Mo}-\mathrm{K} \alpha)$. (a) $P_{\mathrm{N}_{2}}=$ $0.2 \times 10^{5} \mathrm{~Pa}$ (b) $P_{\mathrm{N}_{2}}=0.3 \times 10^{5} \mathrm{~Pa}$ (c) $P_{\mathrm{N}_{2}}=0.6 \times 10^{5} \mathrm{~Pa}$ (d) $P_{\mathrm{N}_{2}}=1.0 \times 10^{5} \mathrm{~Pa}$ (e) Reference pattern from $\delta$ phase (f) Reference pattern from $\gamma$ phase. 
$\mathrm{Nb}-\mathrm{N}$ alloy at $1813 \mathrm{~K}$ under the nitrogen pressure from $0.2 \times 10^{5}$ to $1.0 \times 10^{5} \mathrm{~Pa}$.

\section{Investigation on the phase} transformation of niobium nitride in the course of cooling and solidification

For the purpose of investigating a phase transformation in cooling and solidification, niobium nitride was extracted from the surface of the alloy ingot solidified at the rate of $3 \sim 7$ $\mathrm{K} / \mathrm{s}$ after the high temperature X-ray diffrac- tion, and X-ray diffraction pattern for the niobium nitride was measured at room temperature. Typical example with $\mathrm{Cu}-\mathrm{K} \alpha$ radiation is shown in Fig. 3(a) for the alloy obtained under the nitrogen pressure of $0.6 \times 10^{5} \mathrm{~Pa}$. The reference patterns for $\delta$ and $\gamma$ phases by Brauer et al. ${ }^{(6)(10)}$ are also shown in Fig. 3(b) and (c) respectively. As is seen from Fig. 3, the experimental pattern (Fig. 3(a)) for niobium nitride agrees well with the reference pattern (Fig. 3(b)) for $\delta$ phase. This fact suggests that

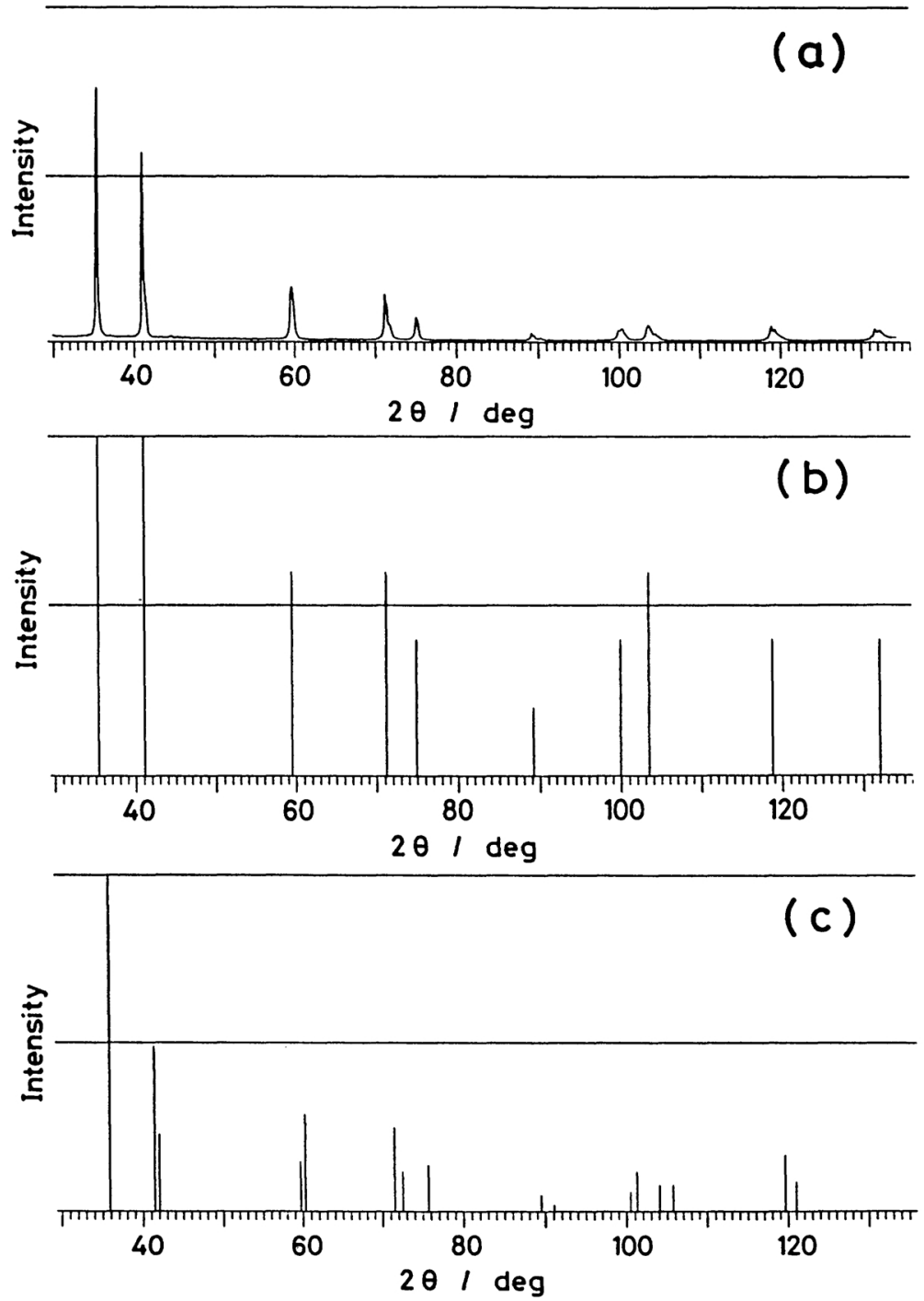

Fig. 3 X-ray diffraction pattern from niobium nitride extracted from the surface of the alloy ingot at room temperature $(\mathrm{Cu}-\mathrm{K} \alpha)$. (a) $P_{\mathrm{N}_{2}}=0.6 \times 10^{5} \mathrm{~Pa}$ (b) Reference pattern from $\delta$ phase (c) Reference pattern from $\gamma$ phase. 
the phase transformation did not occur in niobium nitride. Similar patterns to Fig. 3(a) were obtained for all of the niobium nitride specimens extracted in a similar way. These results agree with the previous result for niobium nitride obtained under one atmospheric pressure of nitrogen. Therefore, it is considered that the phase of the niobium nitride in equilibrium with liquid $\mathrm{Fe}-\mathrm{Nb}-\mathrm{N}$ alloy at $1813 \mathrm{~K}$ under the nitrogen pressure of $0.2 \times 10^{5} \sim 1.0 \times 10^{5} \mathrm{~Pa}$ did not change but remain $\delta$ phase in the course of cooling and solidification at the rate of $3 \sim 7 \mathrm{~K} / \mathrm{s}$.

In order to test the effect of cooling rate on the transformation of niobium nitride, an additional experiment was performed as follows: The liquid $\mathrm{Fe}-\mathrm{Nb}-\mathrm{N}$ alloy of about $100 \mathrm{~g}$ after equilibrated at $1823 \mathrm{~K}$ under the nitrogen pressure of $0.3 \times 10^{5} \mathrm{~Pa}$ was cooled very slowly in a high frequency induction furnace, and niobium nitride extracted from the $\mathrm{Fe}-\mathrm{Nb}-\mathrm{N}$ alloy ingot has been used for X-ray diffraction. From this experiment, niobium nitride was found to be in $\gamma$ phase which had been found by Evans and Pehlke ${ }^{(11)}$ as the equilibrium phase. These results suggest that the $\gamma$ phase, reported by Evans and Pehlke ${ }^{(11)}$, might be produced from the transformation of $\delta$ phase owing to slow cooling, although their experimental condition has not been reported in detail.

\section{Lattice parameter and composition of niobium nitride}

In order to investigate the composition of niobium nitride according to the relation between lattice parameter and nitrogen content, the lattice parameter of niobium nitride was estimated from the diffraction patterns. Table 1 shows the lattice parameters at $1813 \mathrm{~K}$ under various pressure of nitrogen, and those of niobium nitride at $298 \mathrm{~K}$ which was extracted from the surface of the solidified ingot. Table 1 also contains the results obtained in the previous work ${ }^{(5)}$. The lattice parameters obtained at $1813 \mathrm{~K}$ in the present work were not so different from that $(0.445 \mathrm{~nm})$ in the previous work. These values, scattered widely, might have large errors due to the experimental difficulties at high temperature. The lattice parameters at $298 \mathrm{~K}$ were obtained as averaged
Table 1 The lattice parameters of $\delta$-niobium nitride, determined from the high temperature X-ray diffraction patterns and extracted from the solidified alloy ingot.

\begin{tabular}{ccc}
\hline \hline & \multicolumn{2}{c}{ Lattice parameter $/ \mathrm{nm}$} \\
\cline { 2 - 3 }$P_{\mathrm{N}_{2}} / 10^{5} \mathrm{~Pa}$ & $1813 \mathrm{~K}^{*}$ & $298 \mathrm{~K}^{* *}$ \\
\hline 1 & 0.445 & 0.4385 \\
0.6 & 0.442 & 0.4382 \\
0.3 & 0.444 & 0.4383 \\
0.2 & 0.441 & 0.4383 \\
\hline \hline
\end{tabular}

* Mo-K $\alpha$ radiation

** $\mathrm{Cu}-\mathrm{K} \alpha$ radiation

value of several measurements of the X-ray diffraction by $\mathrm{Cu}-\mathrm{K} \alpha$ radiation. These values seemed to be preciser than those at $1813 \mathrm{~K}$ and to be accompanied with the experimental error of $\pm 0.0002 \mathrm{~nm}$. As can be seen in Table 1 , a clear relation could not be found between even the preciser values of lattice parameter and the equilibrium pressure of nitrogen, although it is generally considered that both the lattice parameter and the composition of niobium nitride should vary with the equilibrium pressure of nitrogen.

An attempt has been made to determine the ratio of $\mathrm{N} / \mathrm{Nb}$ by the absorptiometry for the extracted specimens of niobium nitride. However, the resultant values for several runs under the same condition were scattered widely (for example, at $P_{\mathrm{N}_{2}}=0.6 \times 10^{5} \mathrm{~Pa} ; \mathrm{N} / \mathrm{Nb}=$ $0.85 \sim 0.89$ ), and the ratio of $\mathrm{N} / \mathrm{Nb}$ might have errors beyond 0.02 . From these results, no relation could be found either between the ratio of $\mathrm{N} / \mathrm{Nb}$ and the equilibrium pressure of nitrogen.

The values of the lattice parameter at $298 \mathrm{~K}$ and the $\mathrm{N} / \mathrm{Nb}$ ratio of the niobium nitride obtained in the present work are plotted in Fig. 4 together with the results of Brauer and Kirner $^{(12)}$ and Kieda et al. ${ }^{(13)}$ As shown in this figure, the present results nearly corresponded with the other investigators' results within the experimental errors shown above, although neither the lattice parameter nor the ratio of $\mathrm{N} / \mathrm{Nb}$ had a clear relation with the equilibrium pressure of nitrogen, as mentioned above. From the lattice parameters obtained in the present work, the ratio of $\mathrm{N} / \mathrm{Nb}$ could be estimated to be within the range of 0.86 0.89 using the Brauer's relation, for niobium ni- 


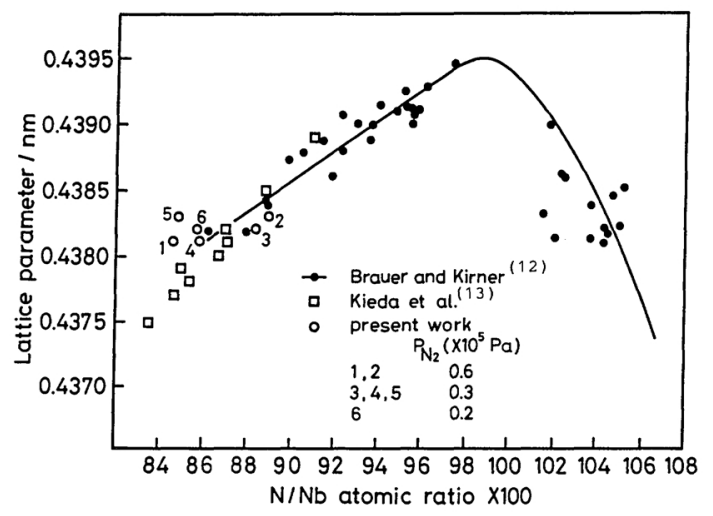

Fig. 4 Relation between the lattice parameter and the ratio of $\mathrm{N} / \mathrm{Nb}$ in $\delta$ niobium nitride.

tride in equilibrium with liquid $\mathrm{Fe}-\mathrm{Nb}-\mathrm{N}$ alloy at $1813 \mathrm{~K}$ under nitrogen pressure of $0.2 \sim$ $1.0 \times 10^{5} \mathrm{~Pa}$. The relation between the ratio of $\mathrm{N} / \mathrm{Nb}$ and the equilibrium pressure of nitrogen will be discussed on the basis of a thermodynamic calculation in the following section.

\section{Thermodynamic Analysis}

As mentioned above, it was very difficult to determine experimentally the precise composition of the niobium nitride in equilibrium with liquid $\mathrm{Fe}-\mathrm{Nb}-\mathrm{N}$ alloy. Accordingly, in the present study, a thermodynamic analysis on the equilibrium between liquid $\mathrm{Fe}-\mathrm{Nb}-\mathrm{N}$ alloy and niobium nitride has been carried out on the basis of sublattice subregular model ${ }^{(14)}$, and the composition of niobium nitride has been estimated.
This model was first developed by Hillert and Staffansson ${ }^{(14)}$ to describe the Gibbs energy of a system which could be supposed to have two sublattices, and later extended by Sundman and $\AA g r e n^{(15)}$ to describe a system which could be supposed to have many sublattices. Recently this model has successfully been applied to the calculation of phase diagram or phase equilibrium, especially in systems including interstitial atoms such as sulfur ${ }^{(16)-(18)}$, carbon $^{(18)-(23)}$, and nitrogen ${ }^{(19)(23)-(25)}$.

\section{Description of Gibbs energy}

In order to describe the Gibbs energy of the $\mathrm{Fe}-\mathrm{Nb}-\mathrm{N}$ system by the sublattice model, it is assumed that each phase contains two sublattices: The host sublattice is completely filled with iron and niobium atoms. The interstitial sublattice is filled with nitrogen atoms and vacancies. Furthermore, the random mixing of atoms is assumed in each sublattice.

The molar integral Gibbs energy of $\mathrm{Fe}-\mathrm{Nb}-$ N system, $G_{m}$, was expressed by the equations proposed by Hillert and Staffansson ${ }^{(14)}$. The equations and further description on this model can be found in the original paper ${ }^{(14)}$.

As for the description of liquid phase, because of a strong interaction between iron and niobium atoms, the composition dependence of the parameters $L_{\mathrm{FeNb}}^{\mathrm{N}}$ and $L_{\mathrm{FeNb}}^{v}$ is introduced as follows:

$$
\begin{aligned}
& L_{\mathrm{FeNb}}^{\mathrm{N}}={ }^{0} L_{\mathrm{FeNb}}^{\mathrm{N}}+\left(y_{\mathrm{Fe}}^{l}-y_{\mathrm{Nb}}^{l}\right)^{1} L_{\mathrm{FeNb}}^{\mathrm{N}}, \\
& L_{\mathrm{FeNb}}^{v}={ }^{0} L_{\mathrm{FeNb}}^{v}+\left(y_{\mathrm{Fe}}^{l}-y_{\mathrm{Nb}}^{l}\right)^{1} L_{\mathrm{FeNb}}^{v} .
\end{aligned}
$$

Hence the Gibbs energy of liquid $\mathrm{Fe}-\mathrm{Nb}-\mathrm{N}$ alloy can be expressed as follows:

$$
\begin{aligned}
G_{m}^{l}= & y_{\mathrm{Fe}}^{l}{ }^{\circ} G_{\mathrm{Fe}}^{l}+y_{\mathrm{Nb}}^{l} G_{\mathrm{Nb}}^{l}+y_{\mathrm{N}}^{l}\left(y_{\mathrm{Fe}}^{l}{ }^{\circ} G_{\mathrm{N}}^{\mathrm{Fe}(l)}+y_{\mathrm{Nb}}^{l}{ }^{\circ} G_{\mathrm{N}}^{\mathrm{Nb}(l)}\right)+y_{\mathrm{Fe}}^{l} y_{\mathrm{Nb}}^{l}\left[y _ { \mathrm { N } } ^ { l } \left\{{ }^{0} L_{\mathrm{FeNb}}^{\mathrm{N}(l)}\right.\right. \\
& \left.\left.+\left(\mathrm{y}_{\mathrm{Fe}}^{l}-y_{\mathrm{Nb}}^{l}\right)^{1} L_{\mathrm{FeNb}}^{\mathrm{N}(l)}\right\}+y_{v}^{l}\left\{{ }^{0} L_{\mathrm{FeNb}}^{v(l)}+\left(y_{\mathrm{Fe}}^{l}-y_{\mathrm{Nb}}^{l}\right)^{1} L_{\mathrm{FeNb}}^{v(l)}\right\}\right]-\left(y_{\mathrm{N}}^{l}\right)^{2}\left(y_{\mathrm{Nb}}^{l} L_{\mathrm{N} v}^{\mathrm{Nb}(l)}+y_{\mathrm{Fe}}^{l} L_{\mathrm{N} v}^{\mathrm{Fe}(l)}\right) \\
& +y_{\mathrm{Nb}}^{l} y_{\mathrm{Fe}}^{l} y_{\mathrm{N}}^{l} y_{v}^{l} L_{\mathrm{N} v}^{\mathrm{FeNb}(l)}+R T\left(y_{\mathrm{Fe}}^{l} \ln y_{\mathrm{Fe}}^{l}+y_{\mathrm{Nb}}^{l} \ln y_{\mathrm{Nb}}^{l}+y_{\mathrm{N}}^{l} \ln y_{\mathrm{N}}^{l}+y_{v}^{l} \ln y_{v}^{l}\right),
\end{aligned}
$$

where the symbol $l$ denotes the liquid phase. All other symbols may be referred to the original paper ${ }^{(14)}$.

From the result of the high temperature $\mathrm{X}$ ray diffractometry, it was clear that the niobium nitride existed as the $\delta$ phase with fcc structure in equilibrium with liquid $\mathrm{Fe}-\mathrm{Nb}-\mathrm{N}$ alloy. Therefore the Gibbs energy of the niobium nitride $\mathrm{NbN}_{\nu}$ can be expressed by the following equation:

$$
G_{m}^{\delta}={ }^{\circ} G_{\mathrm{Nb}}^{\delta}+v^{\circ} G_{\mathrm{N}}^{\mathrm{Nb}(\delta)}-v^{2} L_{\mathrm{N} v}^{\mathrm{Nb}(\delta)}
$$




$$
+R T\{v \ln v+(1-v) \ln (1-v)\} .
$$

In the above equation, the parameter $v$ is the atom ratio of nitrogen to niobium, and represents the non-stoichiometry in niobium nitride. The symbol $\delta$ denotes the fcc structure.

In present calculation, pure nitrogen gas of one atmospheric pressure was chosen as the standard state. ${ }^{\circ} G \mathrm{Fe}(l)$ in eq. (2) represents the hypothetical Gibbs energy for nitrogen in liquid iron at infinite dilution, and is related to the Gibbs energy of pure nitrogen gas ${ }^{\circ} G_{\mathrm{N}_{2}}^{g}$ by the following equation:

$$
{ }^{\circ} G_{\mathrm{N}}^{\mathrm{Fe}(l)}={ }^{\circ} G_{\mathrm{FeN}}^{l}-{ }^{\circ} G_{\mathrm{Fe}}^{l}+L_{\mathrm{N} v}^{\mathrm{Fe}(l)}-\frac{1}{2}{ }^{\circ} G_{\mathrm{N}_{2}}^{g}
$$

${ }^{\circ} G_{\mathrm{N}}^{\mathrm{Nb}()}$ in eq. (2) and ${ }^{\circ} G_{\mathrm{N}}^{\mathrm{Nb}(\delta)}$ in eq. (3) represent similar hypothetical Gibbs energy for nitrogen in liquid and fcc niobium and can be expressed by the equation similar to eq. (4).

2. Calculation of equilibrium between liquid $\mathrm{Fe}-\mathrm{Nb}-\mathrm{N}$ alloy and niobium nitride under nitrogen atmosphere

Three equilibrium phases are concerned in the present system; i.e. gaseous nitrogen, liquid $\mathrm{Fe}-\mathrm{Nb}-\mathrm{N}$ alloy and niobium nitride. When the temperature and pressure are constant, the equilibrium in the system is described by the following equations:

$$
\begin{aligned}
& \mu_{\mathrm{N}}^{l}=\mu_{\mathrm{N}}^{\delta}=\mu_{\mathrm{N}}^{g}, \\
& \mu_{\mathrm{Nb}}^{l}=\mu_{\mathrm{Nb}}^{\delta},
\end{aligned}
$$

where the symbol $g$ stands for gas phase. $\mu_{i}$ is the chemical potential of component $i$ and can be obtained from the equation of the Gibbs energy in each phase. The chemical potential of nitrogen gas can be described by

$$
\mu_{\mathrm{N}}^{g}=\frac{1}{2}{ }^{\circ} G_{\mathrm{N}_{2}}^{g}+R T \ln \sqrt{P_{\mathrm{N}_{2}}},
$$

where $P_{\mathrm{N}_{2}}$ is the nitrogen pressure in atmosphere.

The thermodynamic parameters needed in this calculation were in principle evaluated from the experimental data, and listed in Table 2. Furthermore the Gibbs energy changes due to the phase transformation of pure iron and
Table 2 List of thermodynamic parameters.

\begin{tabular}{lll}
\hline \hline System & \multicolumn{1}{c}{ Parameters $/ \mathrm{J} \cdot \mathrm{mol}^{-1}$} & Reference \\
\hline \multirow{3}{*}{$\mathrm{Fe}-\mathrm{N}$} & ${ }^{\circ} G_{\mathrm{N}}^{\mathrm{Fe}(l)}=9920+47.1 T$ \\
& $L_{\mathrm{N} v}^{\mathrm{Fe}(l)}=-1240+5.9 T$ \\
& ${ }^{\circ} G_{\mathrm{N}(\delta)}^{\mathrm{Nb}(\delta)}=155500-141.1 T$ \\
& $L_{\mathrm{N} v}^{\mathrm{Nb}(\delta)}=173300-118.3 T$ \\
\cline { 2 - 3 } $\mathrm{Nb}-\mathrm{N}$ & ${ }^{\circ} G_{\mathrm{N}(l)}^{\mathrm{Nb}(l)}=-239900+89.8 T$ \\
& $L_{\mathrm{N} v}^{\mathrm{Nb}(l)}=-40000+28.1 T$ \\
\hline \multirow{3}{*}{$\mathrm{Fe}-\mathrm{Nb}$} & ${ }^{0} L_{\mathrm{FeNb}}^{v(l)}=139100-87.0 T$ \\
& ${ }^{1} L_{\mathrm{FeNb}}^{v(l)}=-51570+32.0 T$ \\
$\mathrm{Fe}-\mathrm{Nb}-\mathrm{N}$ & ${ }^{0} L_{\mathrm{FeNb}}^{\mathrm{N}(l)}=4022000-1800 T$ \\
& ${ }^{1} L_{\mathrm{F}(l)}^{\mathrm{N}(l)}=-4212000+1760 T$ \\
& $L_{\mathrm{N} v}^{\mathrm{FeNb}(l)}=-30000$ \\
\hline \hline
\end{tabular}

Table 3 Gibbs energy changes due to the phase transformation presented by Kaufman ${ }^{(31)(32)} / \mathrm{J} \cdot \mathrm{mol}^{-1}$.

$$
\begin{aligned}
& { }^{\circ} G_{\mathrm{Fe}}^{\mathrm{L}}-{ }^{\circ} G_{\mathrm{Fe}}^{\mathrm{bcc}}=13807-7.632 T \\
& { }^{\circ} G_{\mathrm{Nb}}^{\mathrm{L}}-{ }^{\circ} G_{\mathrm{Nb}}^{\text {bcc }}=22928-8.368 T \\
& { }^{\circ} G_{\mathrm{Nb}}^{\mathrm{L}}-{ }^{\circ} G_{\mathrm{Nb}}^{\mathrm{fcc}}=13932-11.924 T
\end{aligned}
$$

niobium, presented by Kaufman, are shown in Table 3.

The calculation was carried out as follows: The parameter $v$, i.e. the composition of niobium nitride, was determined from the eq. (5) for the given temperature and nitrogen pressure. The niobium and nitrogen concentrations were then calculated for liquid $\mathrm{Fe}-\mathrm{Nb}-\mathrm{N}$ alloy in equilibrium with the niobium nitride $\mathrm{NbN}_{\nu}$.

The calculated and experimental results are shown in Fig. 5 for the relation between equilibrium concentrations of niobium and nitrogen in liquid $\mathrm{Fe}-\mathrm{Nb}-\mathrm{N}$ alloy. As is obvious from Fig. 5, the calculated result agrees fairly with the experimental one. Figure 5 also shows that the ratio $\mathrm{N} / \mathrm{Nb}$ of niobium nitride increases monotonously with increase in the equilibrium pressure of nitrogen. The composition of niobium nitride was estimated to vary monotonously from $\mathrm{NbN}_{0.81}$ to $\mathrm{NbN}_{0.87}$ in equilibrium with liquid $\mathrm{Fe}-\mathrm{Nb}-\mathrm{N}$ alloy at $1813 \mathrm{~K}$ under the nitrogen pressure from $0.2 \times 10^{5}$ to $1.0 \times 10^{5} \mathrm{~Pa}$. On the other hand, the composition of niobium nitride estimated from the lattice parameter was $\mathrm{NbN}_{0.86}$ $\mathrm{NbN}_{0.89}$, as mentioned above. These results on 


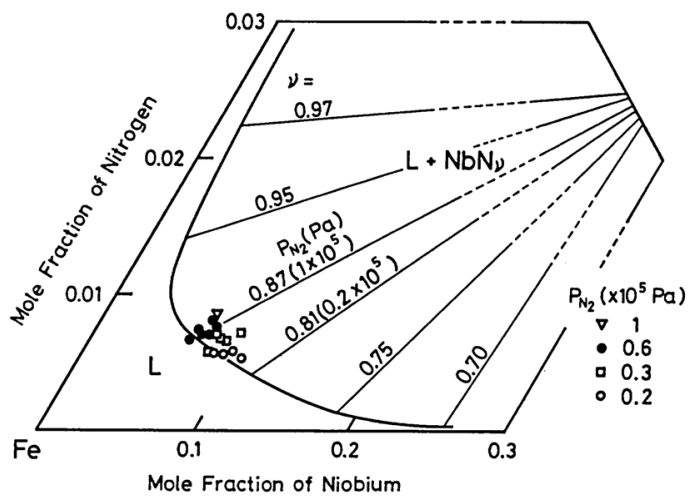

Fig. 5 A comparison between the calculated and the experimental results on the equilibrium between liquid $\mathrm{Fe}-$ $\mathrm{Nb}-\mathrm{N}$ alloy and niobium nitride at $1813 \mathrm{~K}$.

the composition of niobium nitride agreed approximately with each other, considering the errors contained in both estimated values.

Consequently, it was estimated from both the lattice parameter and the thermodynamic analysis that the composition of niobium nitride in equilibrium with liquid $\mathrm{Fe}-\mathrm{Nb}-\mathrm{N}$ alloy at $1813 \mathrm{~K}$ changes monotonously from $\mathrm{NbN}_{0.8}$ to $\mathrm{NbN}_{0.9}$ with the variation of nitrogen pressure from $0.2 \times 10^{5}$ to $1.0 \times 10^{5} \mathrm{~Pa}$.

\section{Conclusion}

By means of high temperature X-ray diffraction, the structure of niobium nitride in equilibrium with liquid $\mathrm{Fe}-(10 \sim 20)$ mass $\%$ $\mathrm{Nb}-\mathrm{N}$ alloy has been determined directly at $1813 \mathrm{~K}$ under the nitrogen pressure of $0.2 \sim 0.6 \times 10^{5} \mathrm{~Pa}$, following the previous investigation under $1.0 \times 10^{5} \mathrm{~Pa}$. The thermodynamic analysis on the equilibrium between liquid $\mathrm{Fe}-\mathrm{Nb}-\mathrm{N}$ alloy and niobium nitride has been carried out using the sublattice subregular model. The results are summarized as follows.

(1) The niobium nitride in equilibrium with liquid $\mathrm{Fe}-(10 \sim 20)$ mass $\% \mathrm{Nb}-\mathrm{N}$ alloy at $1813 \mathrm{~K}$ under the nitrogen pressure of $0.2 \times 10^{5} \sim 1.0 \times 10^{5} \mathrm{~Pa}$ existed as the $\delta$ phase with fcc structure.

(2) The phase of the niobium nitride in equilibrium with liquid $\mathrm{Fe}-\mathrm{Nb}-\mathrm{N}$ alloy did not change, remaining as the $\delta$ phase, in the course of cooling at the rate of $3 \sim 7 \mathrm{~K} / \mathrm{s}$.
(3) The lattice parameter of $\delta$ niobium nitride extracted from the surface of the $\mathrm{Fe}$ $\mathrm{Nb}-\mathrm{N}$ alloy ingot was determined to be $0.4381 \sim 0.4385 \mathrm{~nm}$ at room temperature.

(4) From both the lattice parameter and the thermodynamic analysis, it was estimated that the composition of niobium nitride in equilibrium with liquid $\mathrm{Fe}-\mathrm{Nb}-\mathrm{N}$ alloy at $1813 \mathrm{~K}$ changes monotonously from $\mathrm{NbN}_{0.8}$ to $\mathrm{NbN}_{0.9}$ with the variation in nitrogen pressure from $0.2 \times 10^{5}$ to $1.0 \times 10^{5} \mathrm{~Pa}$.

\section{REFERENCES}

(1) M. Okamoto, R. Tanaka and R. Fujimoto: Tetsu-toHagané, 49 (1963), 613.

(2) K. J. Irvine, F. B. Pickering and T. Gladman: J. Iron Steel Inst., 205 (1967), 161.

(3) T. Gladman and F. B. Pickering: J. Iron Steel Inst., 205 (1967), 653.

(4) Y. Ogino, H. Tanida, M. Kitaura and A. Adachi: Tetsu-to-Hagané, 57 (1971), 533.

(5) Z. Morita, Y. Kita, W.-G. Jung and T. Yanai: Trans. Japan Inst. Metals, 27 (1986), 167.

(6) G. Brauer and R. Esselborn: Z. anorg. allg. Chem., 309 (1961), 151.

(7) R. W. Guard, J. W. Savage and D. G. Swarthout: Trans. Met. Soc. AIME, 239 (1967), 643.

(8) L. E. Toth: Transition Metal Carbides and Nitrides, Refractory Materials Vol. 7, Ed. by J. L. Margrave, Academic Press, New York, (1971), p. 91, p. 92.

(9) Z. Morita, K. Hachisuka, Y. Iwanaga and A. Adachi: J. Japan Inst. Metals, 35 (1971), 831.

(10) G. Brauer and J. Jander: Z. anorg. allg. Chem., 270 (1952), 160.

(11) D. B. Evans and R. D. Pehlke: Trans. Met. Soc. AIME, 233 (1965), 1620.

(12) G. Brauer and H. Kirner: Z. anorg. allg. Chem., 328 (1964), 34.

(13) N. Kieda, N. Mizutani and M. Kato: Yogyo-KyokaiShi, 94 (1986), 73.

(14) M. Hillert and L.-I. Staffansson: Acta Chem. Scand., 24 (1970), 3618.

(15) B. Sundman and J. Ågren: J. Phys. Chem. Solids, 42 (1981), 297.

(16) A. F. Guillermet, M. Hillert, B. Jansson and B. Sundman: Metall. Trans. B, 12B (1981), 745.

(17) M. Hillert and L.-I. Staffansson: Metall. Trans. B, 6B (1975), 37.

(18) H. Ohtani and T. Nishizawa: Trans. ISIJ, 26 (1986), 655.

(19) M. Grujicic, I. Wang and W. S. Owen: CALPHAD, 10 (1986), 117.

(20) Björn Uhrenius: CALPHAD, 8 (1984), 101.

(21) H. Ohtani, M. Hasebe and T. Nishizawa: Trans. ISIJ, 24 (1984), 857.

(22) H. Ohtani, T. Tanaka, M. Hasebe and T. Nishizawa: 
Proceedings of Japan-Canada Seminar on Secondary Steelmaking, Tokyo Japan, (1985), J-7.

(23) J. Ågren: Metall. Trans. A, 10A (1979), 1847.

(24) L. Małdziński, Z. Przyłęcki and J. Kunze: steel res., 57 (1986), 645.

(25) K. Frisk: CALPHAD, 11 (1987), 127.

(26) F. Ishii, S. Ban-ya and T. Fuwa: Tetsu-to-Hagané, 68 (1982), 946.

(27) A. G. Schchurik and I. A. Tomilin: Russ. J. Phys.
Chem., 45 (1971), 1162.

(28) Y. A. Chang and D. C. Hu: Metall. Trans. B, 10B (1979), 43.

(29) J. P. Pemsler: J. Electrochem. Soc., 108 (1961), 744.

(30) H. L. Schick: Thermodynamics of Certain Refractory Compounds, Vol. II, Academic Press, Inc., New York, (1966).

(31) L. Kaufman and H. Nesor: CALPHAD, 2 (1978), 55.

(32) L. Kaufman: CALPHAD, 1 (1977), 7. 